\title{
Benefit-Cost in a Benevolent Society
}

\author{
Theodore C. Bergstrom *
}

May 18, 2004

\section{Introduction}

Alice and Bob live together. Though fond of each other, they maintain separate budgets. They have been offered a chance to rent a larger apartment. The apartment has two extra rooms, a study for Alice and a lounge for Bob. Alice would be willing to pay $\$ 100$ a month to have the study and Bob would be willing to pay $\$ 100$ a month to have the lounge. Alice would never use the lounge and Bob would never use the study, but each likes the other to be happy. For this reason, Alice would be willing to pay $\$ 50$ a month for Bob to have the lounge and Bob would be willing to pay $\$ 50$ a month for Alice to have the study. The additional rent for the larger apartment is $\$ 250$ per month. Should they accept the offer on the grounds that total benefits from the larger apartment are $\$ 300$, or reject it on the grounds that total benefits are only $\$ 200$ ?

More generally, how should benefit-cost analysis account for the value that benevolent individuals place on other people's pleasure from public goods? When adding up the benefits to be compared with costs, should we sum the private valuations, the altruistic valuations, or something else?

An intriguing paper by Viscusi, Magat, and Forrest [26] suggests that benefits from improvements in public health "consist of two components: the private valuation consumers attach to their own health, plus the altruistic valuation that other members of society place on their health." Viscusi et al attempted to measure the two components separately, using a survey in which they asked subjects to state their willingness to pay for a hypothetical product that would reduce their personal risk and also asked for their willingness to pay for an advertising campaign that would result in an equivalent reduction in risk for a larger population. As the authors point out, even a slight concern for the well-being of each member of a large population could amount to a substantial willingness to pay for a public benefit. In a sample of citizens of Greensboro,

\footnotetext{
*Aaron and Cherie Raznick Professor of Economics, University of California, Santa Barbara.
} 
North Carolina, Viscusi and coauthors found that, on average, subjects were willing to pay about 5 times as much to reduce a specific hazard for all North Carolinans as to reduce this hazard for themselves alone. For a similar benefit to all U.S. citizens, subjects would be willing to pay about 6 times as much as for themselves only. Even if these hypothetical claims of altruism are overstated, the magnitude of the altruistic component of public benefits appears to be significant. Thus, the question of how to treat these valuations in benefit-cost analysis becomes a question of the first order of importance.

Before we turn to general matters, let us to try to resolve the rental dilemma for Alice and Bob. Suppose that they decide to rent the larger apartment and split the rent equally. If they take the larger apartment, then on selfish grounds, Alice is worse off, since she is giving up $\$ 125$ in return for a study that she values at only $\$ 100$. Will this private loss be compensated by an improvement in Bob's well-being? Bob is now paying an extra $\$ 125$ in return for a lounge that he values at $\$ 100$. So it appears that when she accounts for her concern for Bob's well-being, she will find the option of taking the apartment even less satisfactory. A symmetric argument applies to Bob's consideration of Alice's well-being. Thus if they base their decision on a comparison of the cost of the apartment with a measure of total benefits which includes the altruistic values of $\$ 50$, they are led to an outcome in which both are worse off. ${ }^{1}$ The story of Alice and Bob illustrates a general principle. If we are to count the altruistic benefits that each gains from the other's enjoyment of the new apartment, we should not forget to also count the cost that each attributes to the fact that the other will have to pay more rent.

In an earlier paper, Bergstrom [2] claimed that in general, when altruism takes a "purely altruistic" form, the appropriate way to measure benefits is to sum private valuations, excluding altruistic valuations. Bergstrom's argument is based on the observation that with pure altruism, the marginal first-order optimality conditions are the same as those that apply if account is taken only of the private valuations. Jones-Lee [16] [17], who referred to Bergstrom's result as "rather arresting," offered a more thorough discussion. Jones-Lee showed that the same conclusion extends to an interesting case of paternalistic preferences, and showed that when concern for others is "safety-focussed" rather than purely altruistic, the appropriate benefit measures are intermediate between the private and social values. In a critical discussion of contingent valuation methods, Milgrom [20] maintained that the appropriate measure of benefits is the sum of private valuations. ${ }^{2}$ Hanemann [12] disputed Milgrom's conclusion on the

\footnotetext{
${ }^{1}$ For those who would like to see a more formal development of this example, the Appendix develops this story within the context of a simple utility theory.

${ }^{2}$ Milgrom's paper appeared in a conference volume, along with an interesting discussion between Milgrom and several environmental economists who found it difficult to accept the assertion that altruistic values should be ignored in benefit-cost studies.
} 
grounds that altruistically motivated valuation is as legitimate as valuation for any other reason.

Johansson [14] suggested that if there is significant altruism, then benefit measures based on contingent valuation studies may lead to overestimates of the benefits of public projects because subjects may inappropriately include their altruistic valuations as well as their private valuations. Johansson proposed that it would be appropriate to ask subjects to state their own willingness to pay for a public project, conditional on the assumption that all others are taxed at rates equal to their private valuations.

This paper seeks general principles for evaluating public projects in a society with altruism. The calculus necessary conditions for a Pareto optimum studied by Bergstrom, Jones-Lee, and Johansson are not exactly what is needed in a benefit-cost analysis. These conditions allow one to determine whether the current state is a local Pareto optimum. If the current state satisfies the relevant first and second-order conditions, then we know that no "small" changes can be Pareto improving. But to satisfy the mission of benefit-cost analysis, we need to consider situations where potential changes are not infinitesimal, and also where neither the status quo nor the alternative is necessarily a Pareto optimum.

\section{What Can Benefit-Cost Analysis Tell Us?}

Before we turn our attention to measuring benefits in societies with benevolence, let us think through the justification for benefit-cost studies in an economy with selfish consumers.

\subsection{Utility Possibilities and Potential Pareto Improvement}

Without explicit instructions about how to compare one person's benefits with the losses of another, we can not expect benefit-cost analysis to tell us whether a public project should or should not be adopted. The best we can hope for from benefit-cost analysis is to learn whether a project is potentially Pareto improving.

Consider a community with two selfish people, one private good and $m$ public goods. An allocation is determined by the quantities of private good for persons 1 and 2 and the vector $y$ of public goods that is available. The two people are endowed with a total of $W$ units of private good, which is to be allocated between consumption for person 1, consumption for person 2, and inputs for the production of public good. Suppose that the amount of private goods needed to produce the vector $y$ of public goods is $C(y)$. Then if the supply of public goods is $y$, the total amount of private goods to be divided between 1 and 2 is $W-C(y)$. Given the vector $y$ of public goods, each feasible distribution 
of private goods determines a distribution of utilities between persons 1 and 2 . We define the graph of such utility distributions to be the $y$-contingent utility possibility frontier. One such curve is shown as $U P(y)$ in Figure 1.

Figure 1: Utility Possibilities and benefit-cost

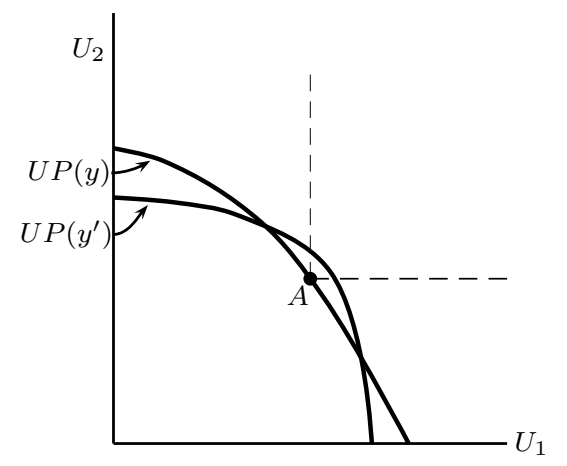

Suppose that a public project will increase the amounts of public goods from $y$ to $y^{\prime}$ at a cost of some reduction in total private consumption. With the project in place, there is a new utility possibility frontier $U P\left(y^{\prime}\right)$. In Figure 1 , neither of the two curves, $U P(y)$ and $U P\left(y^{\prime}\right)$ lies entirely beneath the other. Thus there is no unambiguous way to determine which is the better outcome. Some utility distributions are attainable only if the project is implemented and others are attainable only if it is not.

Let us suppose that initially the amount of public goods is $y$ and that the distribution of private goods corresponds to the utility allocation marked $A$ in the figure. We see that the curve $U P\left(y^{\prime}\right)$ includes points that are above and to the right of $A$. This implies that it is possible to change the supply of public goods from $y$ to $y^{\prime}$ and still have enough private goods left over so that both individuals can be made better off than they were at $A$. When this is the case, we say that the project is potentially Pareto improving.

These ideas extend naturally to the case of more than two consumers. Where $x_{i}$ is private consumption of consumer $i$, the set of all feasible allocations is $\left\{\left(x_{1}, \ldots, x_{n}, y\right) \mid \sum x_{i}+C(y) \leq W\right\}$, where $C(y)$ is the cost in terms of private goods of producing the vector $y$ of public goods. The $y$-contingent utility possibility frontier in $n$ dimensions is then defined in the obvious way.

Definition 1 Suppose that the initial allocation of private and public goods is $A=\left(x_{1}, \ldots, x_{n}, y\right)$. A change in the amount of public goods from $y$ to $y^{\prime}$ is potentially Pareto improving if there exists a feasible allocation $A^{\prime}=$ $\left(x_{1}^{\prime}, \ldots, x_{n}^{\prime}, y^{\prime}\right)$ such that $A^{\prime}$ is Pareto superior to $A$. 


\section{$2.2 \quad$ A Benefit-cost Test}

Where the initial allocation is $A=\left(x_{1}, \ldots, x_{n}, y\right)$, we define an individual's willingness-to-pay for changing the vector of public goods from $y$ to $y^{\prime}$ as the quantity of private goods that she would be willing to sacrifice in return for this change. This number could be either positive or negative, depending on whether $i$ prefers $y^{\prime}$ to $y$ or vice versa.

Definition 2 If the initial allocation is $(x, y)=\left(x_{1}, \ldots, x_{n}, y\right)$, then individual $i$ 's willingness to pay for changing the amount of public goods to $y^{\prime}$ is $w_{i}$ where $w_{i}$ solves the equation $U_{i}\left(x_{i}-w_{i}, y^{\prime}\right)=U_{i}\left(x_{i}, y\right)$.

For an economy with selfish individuals, a simple benefit-cost test determines whether a change is potentially Pareto improving.

Theorem 1 If individuals are selfish and the initial allocation is $(x, y)$ where $\sum_{i} x_{i}+C(y)=W$, then a change in the amount of public goods from $y$ to $y^{\prime}$ is potentially Pareto improving if and only if the sum of individual willingnessesto-pay for the change exceeds the difference in cost $C\left(y^{\prime}\right)-C(y)$.

A detailed proof of Theorem 1 is found in the Appendix. But the idea behind the proof is quite simple. If the sum of willingnesses-to-pay exceeds total cost, then it is possible to change the amount of public goods from $y$ to $y^{\prime}$ and pay for this change by collecting an amount from each individual that is smaller than her willingness to pay. Doing so constitutes a Pareto improvement. Conversely, if the change is potentially Pareto improving, there must be a way to distribute the costs of the change so that nobody is worse off after the project is implemented and cost shares are assigned. By definition, this implies that each individual's share of the cost is smaller than his willingness-to-pay for the project. Since the cost shares add to the total cost of the project it follows that the project would pass the benefit-cost test.

\subsection{A Calculus-Based Necessary Condition}

Theorem 1 is very general in the sense that it does not depend on preferences being convex or continuous and it applies whether the change being considered is large or infinitesimal. But the weakness of this theorem is that it only gives us a way to evaluate projects one at at time. Applying the benefit-cost criterion in this theorem would requires a separate survey of consumers to determine the merits of every possible public project.

If we are willing to assume that preferences are smooth and convex, then calculus-based methods allow us to make more sweeping judgments about the direction of potential Pareto improvements, which depend simply on a comparison of marginal costs and marginal willingnesses to pay. The first order 
necessary condition for efficient provision of public goods was elucidated by Samuelson [22] and is known as the Samuelson condition. This condition requires that at an interior Pareto optimum, for each public good, the sum of all consumers' marginal rates of substitution between that public good and the private goods is equal to the marginal cost of that public good.

While the Samuelson condition can be used to determine whether an existing allocation is Pareto optimal, this is not exactly the result that is needed for benefit-cost analysis. The task of benefit-cost studies is to determine whether specific changes in the amount of public goods could be financed in a way that the outcome is Pareto improving. In a "convex environment," it turns out that a simple extension of Samuelson's result allows one to determine whether an increase or decrease in the amount of public goods is potentially Pareto improving.

Definition 3 At a feasible allocation $(x, y)$, we say that an increase in the amount of public good $j$ passes (fails) the Samuelson test if at the allocation $(x, y)$ the sum of marginal rates of substitution between public good $j$ and the private good is greater than (less than) the marginal cost $C_{j}(y)$ of public good $j$.

Under appropriate convexity assumptions, the Samuelson test gives us simple necessary conditions for an increase or for a decrease in the amount of a public good to be potentially Pareto improving. A proof of the following result is found in the Appendix.

Theorem 2 If preferences of each individual are selfish and convex and if the cost function $C(y)$ is convex in $y$, then a necessary condition for an increase in the amount of public goods to be potentially Pareto improving is that an increase passes the Samuelson test. A necessary condition for a decrease in the amount of public goods to be potentially Pareto improving is that an increase fails the Samuelson test.

\subsection{Benefit-Cost as a First Step}

An attractive feature of benefit-cost analysis is that it seems to allow analysts to make policy recommendations about specific public expenditures without taking a stand on questions of income distribution. This independence of distributional considerations is achieved by focussing on potential rather than actual Pareto improvements. Efforts to construct a useful benefit cost analysis in the absence of distributional judgments has a long history in economics. In 1939, Kaldor [18] and Hicks [13] articulated the view that has come to be known as the New Welfare Economics, and which centers on the "compensation principle." The compensation principle states that an institutional change constitutes an improvement if it is possible for the gainers to compensate the losers for their 
losses and still be better off after the change, whether or not the redistribution actually takes place. ${ }^{3}$

The modern consensus is that the case for distribution-independent project evaluation is much weaker than was originally hoped. Samuelson [21] demonstrated that if the utility possibility sets corresponding to alternative policies are not nested, then the social orderings implied by these criteria are highly unsatisfactory. Chipman and Moore point out that in economies with several private goods and no public goods, nesting of the utility possibility sets requires essentially that preferences be identical and homothetic, or with some further qualifications, of the Gorman polar form. Bergstrom and Cornes [1] show that for an economy with public goods, utility possibility sets corresponding to amounts of public goods will be nested only under special circumstances that are formally dual to the Gorman polar form.

It is noteworthy that Hicks' founding manifesto of the New Welfare Economics [13], does not appear to advocate acceptance of reforms that pass the compensation test if compensation is not actually paid. Hicks states that

"The main practical advantage of our line of approach is that it fixes attention on compensation. Every simple economic reform inflicts a loss on some people... Yet when such reforms have been carried through in historical fact, the advance has usually been made amid the clash of opposing interests, so that compensation has not been given, and economic progress has accumulated a roll of victims, sufficient to give all sound policy a bad name." [13], p. 711

Much of the controversy surrounding the use of the criterion of "potential Pareto improvement" seems to be avoidable if we think of benefit-cost analysis as only a first step in a project evaluation. For example, if an increase in the amount of a public good passes the marginal Samuelson test, then we know that some increase in the amount of the public good is potentially Pareto improving. Of course this does not mean that every possible way of implementing the project is Pareto improving. All we know is that there would be some way of increasing the amount of this public good and dividing costs so that everyone benefits. The next step in evaluation of the project is to consider alternative ways of financing this project and estimating who will then be the winners and the losers. Incentive problems will normally prevent policy makers from knowing exactly how much each individual values the project and so estimates of the distribution of winners and losers will be statistical and not exact. It is usually not reasonable to expect that literally everyone will be better off after the change, but may be possible to use available information to ensure that a

\footnotetext{
${ }^{3}$ An elegant and enlightening intellectual history of the compensation principle and the New Welfare Economics is found in Chipman [8]. Chipman and Moore [7] present a rigorous treatment of these issues, using modern techniques.
} 
very large fraction of the population benefits from the policy and that very few individuals are significantly harmed.

There is an interesting asymmetry in the results of a marginal benefit-cost tests. If an increase in the amount of a public good fails the test, then it must be that there is no way to divide the costs of the project in such a way to achieve a Pareto improvement. The project can reasonably be described as "special interest legislation". To make a case in favor of a project that fails the test, one would need to argue that implementing this project and paying for it with a specified tax scheme is likely to achieve redistributive goals that for some reason could not be more efficiently achieved through redistribution of private goods.

\section{Benevolence and benefit-cost}

\subsection{Altruistic Preferences and Private Values}

Let us now apply benefit-cost analysis to an economy where some people have benevolent feelings toward others. We define $i$ to be purely altruistic to $j$ if $i$ 's sympathy for $j$ is in agreement with $j$ 's perception of her own well-being. This notion is especially easy to formulate in a model with some "private goods" and some "public goods." Let $x_{i}$ be the vector of private goods consumed by person $i$ and let $y$ be the vector of public goods supplied. An allocation $(x, y)=\left(x_{1}, \ldots, x_{n}, y\right)$ specifies the private consumption of each $i$ and the vector of public goods available to the entire community. For each $i$, let there be a private utility function $v_{i}\left(x_{i}, y\right)$ representing $i$ 's private preferences. We say person $i$ is purely altruistic if $i$ has preferences over allocations that can be represented by a "social utility function"

$$
U_{i}(x, y)=U_{i}\left(v_{1}\left(x_{1}, y\right), \ldots, v_{n}\left(x_{n}, y\right)\right)
$$

where $U_{i}$ is an increasing function of $v_{i}$ and a non-decreasing function of $v_{j}$ for all $j \neq i{ }^{4}$

We can define person $i$ 's private value for a change in the amount of public goods as $i$ 's willingness to pay for the change, accounting only for $i$ 's private utility.

Definition 4 If person $i$ has private consumption $x_{i}$, then $i$ 's private value for the change from $y$ to $y^{\prime}$ units of public goods is the solution $w_{i}$ to the equation $v_{i}\left(x_{i}-w_{i}, y^{\prime}\right)=v_{i}\left(x_{i}, y\right)$.

\footnotetext{
${ }^{4}$ Bergstrom [3] and [4] shows that under reasonable conditions, the existence of a utility representation of the form (1) is implied by the existence of utility functions such that for each $i, U_{i}$ depends on $i$ 's private utility $v_{i}\left(x_{i}, y\right)$ and the altruistic utilities, $U_{j}$ of all other individuals
} 


\subsection{A Private Values benefit-cost Test}

Where preferences are purely altruistic, we can define a private values benefitcost test as follows.

Definition 5 Suppose that the initial allocation in an economy is $(x, y)$. A public project that changes the amount of public goods from $y$ to $y^{\prime}$ passes the private value benefit-cost test if the sum of all persons' private values for the change from $y$ to $y^{\prime}$ units of public goods exceeds the cost difference $C\left(y^{\prime}\right)-C(y)$.

We will say that a project is potentially privately improving if it is possible to implement the project and pay for it in such a way that somebody's private utility increases and nobody's private utility decreases. More formally:

Definition 6 If the initial allocation is $(x, y)$, a change in the amount of public goods from $y$ to $y^{\prime}$ is potentially privately improving if there exists a feasible allocation $\left(x^{\prime}, y^{\prime}\right)$ such that $v_{i}\left(x_{i}^{\prime}, y^{\prime}\right) \geq v_{i}\left(x_{i}, y\right)$ for all $i$ with strict inequality for some $i$.

The same reasoning that established Theorem 1 shows that a project is potentially privately improving if and only if the sum of private values for the project exceeds its total cost. Since the social utility functions $U_{i}$ are increasing in $v_{i}$ and nondecreasing in $v_{j}$ for all $j \neq i$, it follows that an increase in all of the private utilities $v_{j}$ is a sufficient condition for an increase in each of the social utilities $U_{i}$. Therefore we can conclude that:

Remark 1 If preferences are purely altruistic, then a change in the amount of public goods is potentially Pareto improving if it passes the private value benefitcost test.

\subsection{Sufficient but not Necessary}

Although any project that passes the private value benefit-cost test is potentially Pareto improving, the converse is not true. When altruism is present, the private values benefit-cost test is sometimes "too demanding" in the sense that it rejects potentially Pareto improving changes. Because individuals care about the well-being of others, there may be Pareto improvements in which reductions in private utility for some individuals are compensated by increases in private utilities for others whom they care about.

Figure 2 illustrates a potentially Pareto improving change that fails the private value benefit-cost test. The figure displays private utilities $v_{i}$ on the axes. The curve $U P(y)$ shows the private utility distributions attainable if the amount of public good is $y$. The point $A=\left(v_{1}\left(x_{1}, y\right), v_{2}\left(x_{2}, y\right)\right)$ is the

distribution of private utilities in the initial allocation. The area $V^{+}$above and 
to the right of the dashed lines shows all of the "privately improving" outcomes where every consumer's private utility is higher than at the point $A$. The area above the curve $U^{1} U^{1}$ represents combinations of $v_{1}$ and $v_{2}$ that person 1 prefers to the outcome $A$ and the area above $U^{2} U^{2}$ represents combinations of $v_{1}$ and $v_{2}$ that person 2 prefers to $A$, taking account of altruistic preferences. The private utility distributions corresponding to outcomes that that are Pareto superior to $A$ are those that are above both of these two curves, which is the area above the curve, $U^{2} A U^{1}$.

Figure 2: Pareto-Improving Transfers

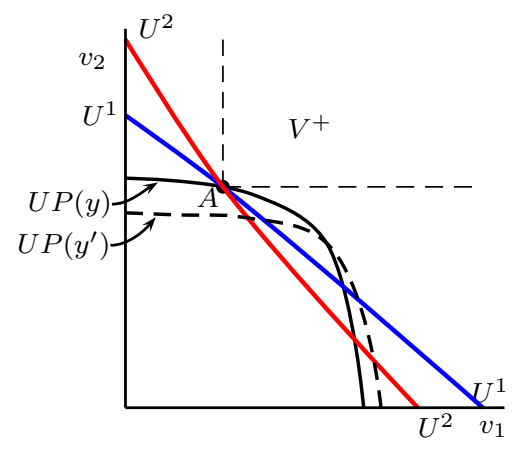

A project that changes the supply of public goods from $y$ to $y^{\prime}$ passes the private value benefit-cost test if and only if the $y^{\prime}$-contingent utility possibility frontier $U P\left(y^{\prime}\right)$ intersects the region $V^{+}$. In Figure 2, the curve $U P\left(y^{\prime}\right)$ does not intersect $V^{+}$, but does pass through the region above the curve $U^{2} A U^{1}$. Therefore a change in the amount of public goods from $y$ to $y^{\prime}$ fails the private value benefit-cost test, but is potentially Pareto improving.

Remark 2 With purely altruistic preferences, the private value benefit-cost test is not a necessary condition for a change in the amount of public goods to be potentially Pareto improving.

Indeed in Figure 2, we see that the $y$-contingent utility utility possibility curve $U P(y)$ also intersects the region above $U^{2} A U^{1}$, which means that it would be possible to achieve a Pareto improvement simply by redistributing private income, without a change in the amount of public goods.

On reflection, it is apparent that if a Pareto improvement can be accomplished by redistribution of private goods, then even an entirely wasteful (but small) change in public expenditure could qualify as potentially Pareto improving. This suggests that if we seek useful benefit-cost criteria, we need to consider changes that start from an allocation from which no Pareto improvements can 
be achieved simply redistributing private goods. It will be useful to define distributionally efficient allocations as follows:

Definition 7 An allocation $(x, y)$ is distributionally efficient if there is no feasible allocation $\left(x^{\prime}, y\right)$ that is Pareto superior to $(x, y)$.

In Figure 3, the allocation $A$ is distributionally efficient. In this figure allocations that are Pareto superior to $A$ must lie in the region that is above the two curves $U_{1} U_{1}$ and $U_{2} U_{2}$. Since the curve $U P(y)$ does not cross into this region, there is no way to achieve a Pareto improvement simply by redistribution of private goods.

Figure 3: A Distributionally Efficient Allocation

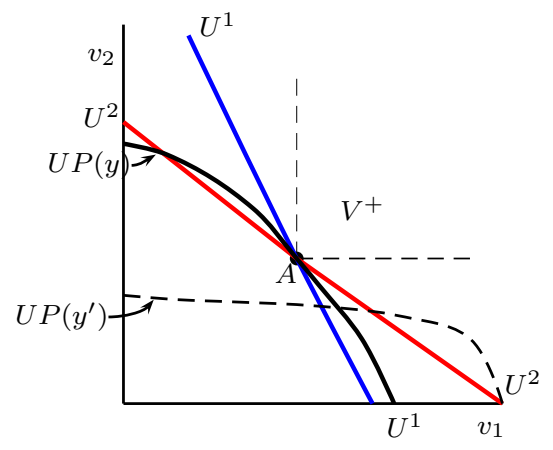

Even if the initial allocation is distributionally efficient, passing the private value benefit-cost test is not a necessary condition for a change in the amount of public goods to be potentially Pareto improving. We can see this from the example in Figure 3. In this diagram, the $y^{\prime}$-contingent utility possibility frontier does not intersect $V^{+}$and hence $y^{\prime}$ does not pass the private values benefit-cost test. Nevertheless, since $U P\left(y^{\prime}\right)$ intersects the area above the two curves $U_{1} U_{1}$ and $U_{2} U_{2}$, there exists a feasible allocation $\left(x^{\prime}, y^{\prime}\right)$ that is Pareto superior to $(x, y)$. Thus a change in the public goods supply from $y$ to $y^{\prime}$ is potentially Pareto improving.

As this example illustrates, we can not hope to find a benefit-cost test that is based only on private values and that yields "global" necessary and sufficient conditions for potential Pareto improvement.

\subsection{A Useful Necessary Condition}

The previous section showed that in an economy with pure altruism, passing the private value benefit-cost test is a sufficient but not a necessary condition 
for a project to be potentially Pareto improving. In fact, we showed that even if the initial allocation is distributionally efficient, there may be changes in the amount of the public goods that fail the private value benefit-cost test, but are potentially Pareto improving. Nevertheless, it turns out that, subject to some fairly weak technical assumptions, there is a simple marginal condition that depends only on private evaluations and is necessary for a change to be potentially Pareto improving. The following definitions are helpful for stating this result.

Definition 8 Consumer $i$ 's private marginal rate of substitution between public good $j$ and private goods is the ratio $m_{i j}\left(x_{i}, y\right)$ between the partial derivative of $v_{i}\left(x_{i}, y\right)$ with respect to $y_{j}$ and the partial derivative of $v_{i}\left(x_{i}, y\right)$ with respect to $y$.

We define the desired condition as follows.

Definition 9 At the allocation $(x, y)$, public good $j$ is said to pass the private values Samuelson test if

$$
\sum_{i} m_{i j}(x, y)>C_{j}(y) .
$$

and to fail the private values Samuelson test if if this inequality is reversed.

The necessary condition that we seek will be valid under the following assumptions.

A. 1 Each consumer $i$ has purely altruistic preferences, with a social utility function $U_{i}\left(v_{1}, \ldots, v_{n}\right)$ that is quasi-concave, differentiable, nondecreasing in all $v_{j}$ and increasing in $v_{i}$.

A. 2 The private utility functions $v_{i}\left(x_{i}, y\right)$ are concave, differentiable, and increasing in $x_{i}$.

A. 3 The set of feasible allocations is $\left\{(x, y) \mid \sum_{i} x_{i}+C(y) \leq W\right\}$, where the cost function $C(y)>0$ is convex in $y$.

Theorem 3 In an economy where Assumptions A.1-A.3 are satisfied and where the initial allocation $(\bar{x}, \bar{y})$ is distributionally efficient, a necessary condition for an increase in the amount of public good $j$ to be potentially Pareto improving is that public good $j$ does not fail the private values Samuelson test. Similarly, a necessary condition for a decrease in the amount of public good $j$ to be potentially Pareto improving is that public good $j$ does not pass the private values Samuelson test. 
Proof or Theorem 3. The first claim of this theorem is that if public good $j$ fails the private values Samuelson test, then no increase in the amount of $j$ can be potentially Pareto improving. To show this, let $(\bar{x}, \bar{y})$ be the initial allocation. If public good $j$ fails the Samuelson test, then, as is demonstrated in Lemma 1 of the Appendix, there is some decrease in the amount of public good $j$ that is potentially Pareto improving. That is, there exists a feasible allocation $(x, y)$ such that $y_{j}<\bar{y}, y_{k}=\bar{y}_{k}$ for $k \neq j$ and $(x, y)$ is Pareto superior to $(\bar{x}, \bar{y})$. Suppose that an increase in the amount of public good $j$ from $\bar{y}_{j}$ to $y_{j}^{\prime}$ is potentially Pareto improving. Then there exists a feasible allocation $\left(x^{\prime}, y^{\prime}\right)$ that is Pareto superior to $(\bar{x}, \bar{y})$. Since $y_{j}^{\prime}>\bar{y}_{j}>y_{j}$, there is some $\lambda \in(0,1)$ such that $\bar{y}=\lambda y+(1-\lambda) y^{\prime}$. Consider the allocation $\lambda(x, y)+(1-\lambda)\left(x^{\prime}, y^{\prime}\right)$. The assumption that $C$ is a convex function implies that this allocation is feasible. Since $(x, y)$ and $\left(x^{\prime}, y^{\prime}\right)$ are both Pareto superior to $(\bar{x}, \bar{y})$, assumptions in A.1 and A.2 on the convexity of preferences imply that $\lambda(x, y)+(1-\lambda)\left(x^{\prime}, y^{\prime}\right)=$ $\left(\lambda x+(1-\lambda) x^{\prime}, \bar{y}\right)$ is Pareto to superior to $(\bar{x}, \bar{y})$. But this contradicts the assumption that the initial allocation is distributionally efficient. It follows that if an increase in the amount public good $j$ fails the private values Samuelson test, then a small decrease in the amount of public goods is potentially Pareto improving and no increase in the amount of public goods can be potentially Pareto improving.

A parallel line of reasoning shows that if an increase in the amount of a public good passes the private values Samuelson test, then a small increase in the amount of that public good is potentially Pareto improving and no decrease is potentially Pareto improving.

\subsection{A Puzzling Observation Explained}

Section 3.3 showed an example where an increase in the amount of a public good is potentially Pareto improving, even though this change fails a private values benefit-cost test. Consumer 2's altruism towards Consumer 1 is sufficient for him to prefer the new allocation to the old, even though his private utility is lower after the change.

Since it is possible to achieve a Pareto improvement without increasing private utilities of every consumer, how can the private values Samuelson condition, which accounts only for private marginal rates of substitution, be a necessary condition for an increase in the amount of a public good to be Pareto improving?

The explanation of this seeming paradox is as follows. The proof of Theorem 3 demonstrates that if the initial allocation is distributionally efficient and if certain convexity and continuity conditions are satisfied, then whenever an increase in the amount of a public good is potentially Pareto improving in terms of the altruistic utilities $U_{i}$, it must be that a decrease in the amount of this public good is not potentially Pareto improving in terms of the private utilities, 
$v_{i}$. But a decrease in the amount of a public good will be potentially Pareto improving in terms of the private utilities if that public good fails the private values Samuelson condition. Therefore, under the assumptions of Theorem 3, a necessary condition for an increase in the amount for a public good to be potentially Pareto improving when altruism is taken into account is that the public good does not fail the private goods Samuelson condition.

\section{Discussion and Applications}

What have we learned that can guide policy-makers and practitioners? The story of Alice and Bob suggests that there is reason to heed Johansson's [14] warning that ill-formed contingent evaluation studies may yield misleading results. Imagine that Alice and Bob hired a naive benefit cost analyst to decide whether they should take the new apartment. If the analyst asked each of them, "How much would you be willing to pay to have the larger apartment?" they would each reply $\$ 150$. The analyst would then report total benefits of $\$ 300$ and recommend that they take the apartment so long as the extra rent did not exceed $\$ 300$. But if the rent is more than $\$ 200$ and is split equally between them, they will both be worse off if they take the apartment. What went wrong? The analyst evidently asked the wrong question. This question encouraged answers that include the sympathetic value that each places on the other's utility for the new apartment but neglect the sympathetic cost that each would feel because the other has to pay more rent.

The analyst might instead have asked each of them. "If the cost of moving to the new apartment is split equally between you, what is the most that you yourself would be willing to pay for the larger apartment?" Then each would take account of the costs as well as the benefits to the other, and each would answer $\$ 100$. The analyst would then correctly recommend taking the apartment only if the extra rent did not exceed $\$ 200$. The symmetry of this example makes it natural for the decision-maker to propose splitting costs equally. But in less symmetric circumstances, it would not be obvious what division of costs to propose. In principle, the analyst could discover potential improvements, but this might require asking many different questions, each of which proposed a different division of costs.

Our results suggest that for many purposes, a simpler approach will suffice. In the case of Alice and Bob, the analyst could ask each of them a single question. "How much would you be willing to pay for the benefits that you yourself realize from the larger apartment, ignoring any benefits to the other person?" Moving to the larger apartment will be potentially Pareto improving if and only if the sum of these two measures of benefit exceeds the additional cost.

More generally, Theorem 3 tells us that the private values Samuelson test 
can determine the appropriate direction of change in the quantity of any public good. For this test, marginal benefits might be determined by asking a question like: "How much would you be willing to pay per unit for a small increase in the amount of this public good ignoring any benefits (or costs) that may be accrue to others.

Benefit cost studies based on surveys in which individuals are asked their willingness to pay for public amenities are routinely used by government agencies in many countries. As Hanemann [12] and Carson [6] explain, these studies vary widely in design and in quality. While there has been an energetic debate over the validity of contingent evaluation studies, Hanemann reviews a body of evidence that suggests that carefully conducted contingent valuation studies exhibit reliability and consistency with other measures of willingness to pay.

For some projects that improve public health and safety, it is relatively easy to distinguish private values from altruistically motivated values. Several interesting studies have involved interviews of a sample of individuals, who are asked for their valuations of hypothetical changes in the risk of various adverse health effects. These studies carefully frame the hypothetical situations so as to distinguish between subjects' valuations of the effects on their own health and the value that they place on health benefits to others. Viscusi and his coauthors [26] asked their subjects what they would pay for a product that would increase their own safety, but not that of others, and then separately asked about willingness to pay for extending the same benefits to a larger population. Jones-Lee, Hamerton, and Philips [15] asked a sample of British adults about their willingness to pay for a hypothetical safety device on their own cars that would increase only the driver's safety. A second question asked about their willingness to pay for a device that the increased the safety of the passengers as well as the driver. Dickie and Ulery [11] and Dickie and Gerking [10] asked parents to state the amount that they would be willing to pay to spare their own children from illnesses with a specific list of unpleasant systems. They also asked questions about wilingness to pay to avoid the same symptoms for themselves and for others outside the family.

There have also been several "revealed preference" studies of willingness to pay to avoid private hazards. These are catalogued in a recent survey by Viscusi and Aldy [25] Economists have used data on wages and occupational hazards to estimate the amount the prices at which individuals will accept risks to their own life and limb. Other studies have related the reduction in the price of houses near hazardous wastes to the hazards involved. Others have attempted to hedonic estimates of the value of additional safety features of automobiles.

These health and safety studies avoid the pitfall of which Johansson warns. The contingent valuation surveys focus deliberately on the respondents' private willingness to pay for their own or their childrens' health. Some of these studies 
also elicit separate measures of altruistically motivated willingness to pay. Similarly, the revealed preference studies are able to sort out private willingness to pay from altruistic considerations because they investigate willingness to pay for private goods, like safer cars, that provide close substitutes for increased safety resulting from public goods like highway improvements.

But for many public goods, it is not easy to distinguish private valuations from altruistic values. An especially problematic case is the measurement of "existence value" of wilderness areas or of endangered species, things which people may value even if they never expect to see them. Loomis and White [19] survey a large number of contingent valuation studies of the value of preserving various animal species. Coursey [9] describes a typical question of such studies as: "What is the maximum dollar amount your household would be willing to pay for a program that will lead to a ten percent increase in the whooping crane population?" A contingent valuation studies by Bowker and Stoll [5] (for whooping cranes) and a study by Stevens et al [23] (for bald eagles, Atlantic salmon, wild turkeys, and coyotes) asked how much individuals were willing to contribute voluntarily to a fund that was set up to benefit the targeted animal.

How are we to interpret the answers to Coursey's question? A subject might believe that this question means either: A) How much would you be willing to pay for a ten percent increase in the whooping crane population, if this increase depended solely on your own contribution? B) What is the largest tax increase that you would be willing to accept for you and those like you in order to accomplish a ten percent increase in the whooping crane population? People with strong altruistic motives are likely to respond with a much larger answer to Question A than to Question B. This paper has argued that the conceptually appropriate answer for benefit cost analysis is the answer to Question B. Contingent valuation studies might be improved by sharpening the line of inquiry to clarify whether it is Question A or Question B that is being asked. It would also be useful to conduct comparative studies designed to determine whether Coursey's question is usually interpreted as Question A, as Question B or whether it matters.

There is even more uncertainty about how the subject interprets a question about the size of voluntary contribution that she is willing to make for a public good. This was acknowledged by Stevens, More and Glass [24] in a followup paper to their earlier paper, [23]. The authors re-interviewed subjects of the earlier study and asked them why they would pay for restoration of animal populations. About 40 percent of the subjects responded that they were motivated by concern for doing their "fair share" to help preserve wildlife. Others were motivated by the "pleasure of knowing the population would continue to exist", while others responded that they would "get pleasure from knowing that they had contributed to a good cause. 
Stevens and his coauthors [24] conclude their followup study by remarking that "unless motivations underlying $\mathrm{CV}$ response are identified, existence value estimates will be often misinterpreted." This conclusion seems justified. It would be useful to conduct further studies that investigate subjects' own willingness to pay for an increase in the amount of a public good under explicitly stated assumptions about whether it is assumed that others are also required to contribute.

\section{Appendix}

\section{Alice and Bob with Utility Functions}

Suppose that Alice and Bob have "private utility functions" $v_{A}\left(x_{A}, y_{A}\right)=x_{A}+$ $100 y_{A}$ and $v_{B}\left(x_{B}, y_{B}\right)=x_{B}+100 y_{B}$ where $y_{A}$ is 0 or 1 depending on whether Alice has the study, $y_{B}$ is 0 or 1 depending on whether Bob has the lounge, and $x_{i}$ is private consumption of person $i$. Let Alice and Bob's concern for each other be registered in "altruistic utility functions" $U_{A}\left(v_{A}, v_{B}\right)=v_{A}+v_{B} / 2$ and $U_{B}\left(v_{A}, v_{B}\right)=v_{B}+v_{A} / 2$. Suppose that if they do not take the new apartment, Alice and Bob will have $\bar{x}_{A}$ and $\bar{x}_{B}$, respectively, to spend on other goods. If they take the new apartment at an additional cost of $c$ and split this cost equally, then Alices's expenditure on other goods will be $x_{A}^{\prime}=\bar{x}_{A}-p / 2$ and Bob's will be $x_{B}^{\prime}=\bar{x}_{B}-p / 2$. Thus if they do not take the apartment, their private utilities will be $v_{A}=\bar{x}_{A}$ and $v_{B}=\bar{x}_{B}$ and if they take the apartment, their private utilities will be $v_{A}^{\prime}=x_{A}^{\prime}+100=\bar{x}_{A}+100-p / 2$ and $v_{B}=x_{B}^{\prime}+100=$ $\bar{x}_{B}+100-p / 2$. Now consider their altruistic utility functions. If they do not take the apartment, Alice's utility will be $U_{A}=\bar{x}_{A}+\bar{x}_{B} / 2$ and Bob's utility will be $U_{B}=\bar{x}_{B}+\bar{x}_{A} / 2$. If they take the apartment, Alice's utility will be $U_{A}^{\prime}=\bar{x}_{A}+100-p / 2+\left(\bar{x}_{B}+100-p / 2\right) / 2=U_{A}+150-3 p / 2$ and Bob's utility will be $U_{B}^{\prime}=\bar{x}_{B}=100-P / 2+\left(\bar{x}_{A}+100-p / 2\right) / 2=U_{B}+150-3 p / 2$. Therefore they will both benefit from taking the apartment if $p<\$ 100$ and they will both be worse off if $p>\$ 100$. Evidently in this example, Alice and Bob will make a correct decision if and only if they value the apartment at the sum of their private valuations, ignoring the value that each attributes to the other's enjoyment.

\section{Proof of Theorem 1}

Let $(x, y)$ be the initial allocation and let $w_{i}$ be $i$ 's willingness to pay for the change from $y$ to $y^{\prime}$. Suppose that the sum of willingnesses to pay exceeds $C\left(y^{\prime}\right)-C(y)$. Then there exists $\epsilon>0$ such that $\sum_{i}\left(w_{i}-\epsilon\right)>C\left(y^{\prime}\right)-C(y)$. For each $i$, let $x_{i}^{\prime}=x_{i}-\left(w_{i}-\epsilon\right)$. From the definition of $w_{i}$, it follows that for 
each $i, U_{i}\left(x_{i}^{\prime}, y^{\prime}\right)>U_{i}(x, y)$. Now

$$
\sum_{i} x_{i}^{\prime}=\sum_{i} x_{i}-\sum_{i}\left(w_{i}-\epsilon\right)<\sum_{i} x_{i}-\left(C\left(y^{\prime}\right)-C(y)\right)
$$

Rearranging terms in 3 , we have

$$
\sum_{i} x_{i}^{\prime}+C\left(y^{\prime}\right)<\sum_{i} x_{i}+C(y)<W
$$

Expression 4 implies that that the allocation $\left(x^{\prime}, y^{\prime}\right)$ is feasible. Therefore if the sum of willingnesses to pay for the movement from $y$ to $y^{\prime}$ exceeds $C\left(y^{\prime}\right)-C(y)$, then the change from $y$ to $y^{\prime}$ is potentially Pareto improving.

Conversely, suppose that the change from $y$ to $y^{\prime}$ is potentially Pareto improving. Then there exists a feasible allocation $\left(x^{\prime}, y^{\prime}\right)$ such that $U_{i}\left(x_{i}^{\prime}, y^{\prime}\right) \geq$ $U_{i}\left(x_{i}, y\right)$ for all $i$ with strict inequality for some $i$. From the definition of $i$ 's willingness to pay, $w_{i}$, it follows that $x_{i}-x_{i}^{\prime} \leq w_{i}$ for all $i$ with strict inequality for some $i$ Therefore

$$
\sum_{i} w_{i}>\sum_{i}\left(x_{i}-x_{i}^{\prime}\right)
$$

Since $\sum x_{i}+C(y)=W$ and since feasibility of $\left(x^{\prime}, y^{\prime}\right)$ implies that $\sum x_{i}^{\prime}+$ $C\left(y^{\prime}\right) \leq W$, it must be that

$$
\sum_{i}\left(x_{i}-x_{i}^{\prime}\right) \geq C\left(y^{\prime}\right)-C(y)
$$

Then from Expressions 5 and 6 it follows that $\sum w_{i}>C\left(y^{\prime}\right)-C(y)$.

\section{Proof of Theorem 2}

Let $(\bar{x}, \bar{y})$ be the initial allocation and suppose that $\sum \bar{x}_{i}+C(\bar{y})=W$. If an increase in the amount of public goods to $y>\bar{y}$ is potentially Pareto improving, then there exists a feasible allocation $(x, y)$ that is Pareto superior to $(\bar{x}, \bar{y})$. Where $0<t<1$, let $x_{i}(t)=\bar{x}_{i}+t\left(x_{i}-\bar{x}_{i}\right)$ and $y(t)=\bar{y}+t(y-\bar{y})$. Since preferences are assumed to be convex and $(x, y)$ is Pareto superior to $(\bar{x}, \bar{y})$, it must be that for $0<t<1, U_{i}\left(x_{i}(t), y(t)\right) \geq U_{i}\left(\bar{x}_{i}, \bar{y}\right)$ for all $i$, with strict inequality for some $i$. Therefore it must be that for all $i$, and for $t \geq 0$,

$$
\frac{d}{d t} U_{i}\left(x_{i}(t), y(t)\right)=\frac{\partial U_{i}\left(x_{i}(t), y(t)\right)}{\partial x_{i}}\left(x_{i}-\bar{x}_{i}\right)+\frac{\partial U_{i}\left(x_{i}(t), y(t)\right)}{\partial y}(y-\bar{y}) \geq 0,
$$

with strict inequality for some $i$. Since the inequality in 7 holds for all $t \geq 0$ and since the marginal utility of private goods is assumed to be positive, it follows that for all $i$,

$$
\left(\bar{x}_{i}-x_{i}\right) \geq m_{i}\left(\bar{x}_{i}, \bar{y}\right)(y-\bar{y}),
$$


with strict inequality for some $i$ where we define the marginal rate of substitution

$$
m_{i}(\bar{x}, \bar{y})=\left(\frac{\partial v_{i}\left(\bar{x}_{i}, \bar{y}\right)}{\partial x_{i}} \div \frac{\partial v_{i}\left(\bar{x}_{i}, \bar{y}\right)}{\partial y}\right)
$$

Adding the inequalities in 8 for all $i$, we have

$$
\sum\left(\bar{x}_{i}-x_{i}\right)>S(\bar{x}, \bar{y})(y-\bar{y})
$$

where $S(\bar{x}, \bar{y})$ is the Samuelson $\operatorname{sum} \sum_{i} m_{i}\left(\bar{x}_{i}, \bar{y}\right)$.

Since $(x, y)$ is feasible, it must be that $\sum x_{i}+C(y) \leq W$ and since $\sum \bar{x}_{i}+$ $C(\bar{y})=W$, it follows that

$$
\sum\left(\bar{x}_{i}-x_{i}\right) \geq C(y)-C(\bar{y})
$$

The assumption that $C^{\prime}(y)$ is nondecreasing implies that $C(y)-C(\bar{y}) \geq C^{\prime}(\bar{y})(y-$ $\bar{y})$. Therefore it must be that $S(\bar{x}, \bar{y})>C^{\prime}(\bar{y})(y-\bar{y})$.

\section{Proof of Lemma 1}

Lemma 1 If an increase in the amount of public good $j$ fails the private values Samuelson test, then some decrease in the amount of public good $j$ is potentially Pareto improving.

The idea of the proof is simple and plausible. If the sum of marginal rates of substitution for a public good is less than its marginal cost, then the supply of the public good can be reduced by a small amount and the public goods saved will be more than enough to compensate every consumer for the loss of public goods. We show this formally as follows.

Let $(\bar{x}, \bar{y})$ be the initial allocation and suppose that an increase in $y_{j}$ fails the Samuelson test. Let $\bar{m}_{i j}$ be $i$ 's private marginal rate of substitution between public good $j$ and private goods at this allocation. Since $\sum_{i} \bar{m}_{i j}<C_{j}(\bar{y})$, there exists $\epsilon>0$ such that $\sum_{i}\left(\bar{m}_{i j}+\epsilon\right)<C_{j}(\bar{y})$. For $t>0$, define the allocation $(x(t), y(t))$ so that $x_{i}(t)=\bar{x}_{i}+\left(\bar{m}_{i j}+\epsilon\right) t$ and $y_{j}(t)=y_{j}-t$. This allocation corresponds to a decrease of $t$ in the amount of public goods compensated by an increase of $\left(\bar{m}_{i j}+\epsilon\right) t$ in each $i$ 's private consumption. For each consumer $i$, define $\tilde{v}_{i}(t)=v_{i}\left(x_{i}(t), y(t)\right.$. Since $\bar{m}_{i j}+\epsilon>\bar{m}_{i} j$, it is not hard to show that the derivative of $\tilde{v}_{i}(t)$ is positive at $t=0$ and therefore for some $t^{*}>0$ and all $i, \tilde{v}_{i}\left(t^{*}\right)=v_{i}\left(x_{i}\left(t^{*}\right), y\left(t^{*}\right)\right)>v_{i}\left(\bar{x}_{i}, \bar{y}\right)$.

The allocation $\left(x\left(t^{*}\right), y\left(t^{*}\right)\right)$ is also feasible. Since $\sum_{i}\left(\bar{m}_{i j}+\epsilon\right)<C_{j}(\bar{y})$, we have

$$
\sum_{i} x_{i}\left(t^{*}\right)=\sum_{i} \bar{x}_{i}+t^{*}\left(\bar{m}_{i}+\epsilon\right)<\sum_{i} x_{i}+t^{*} C^{\prime}(\bar{y}) .
$$

The assumption that $C(y)$ is a convex function implies that $C(\bar{y})-C\left(\bar{y}-t^{*}\right) \geq$ $t^{*} C^{\prime}(\bar{y})$ and therefore it follows from Expression 12 that 


$$
\sum_{i} x_{i}\left(t^{*}\right)<\sum_{i} \bar{x}_{i}+C(\bar{y})-C\left(\bar{y}-t^{*}\right)
$$

Since $y\left(t^{*}\right)=y-t^{*}$, it follows from Expression 13 that

$$
\sum x_{i}\left(t^{*}\right)+C\left(y\left(t^{*}\right)\right)<\sum \bar{x}_{i}+C(\bar{y})=W,
$$

which implies that the allocation $\left(x\left(t^{*}\right), y\left(t^{*}\right)\right)$ is feasible. Since this allocation is feasible and privately preferred by all $i$ to $(\bar{x}, \bar{y})$, it follows that a decrease in the amount of public goods from $\bar{y}$ to $\bar{y}-t^{*}$ is potentially Pareto improving.

\section{References}

[1] Theodore Bergstrom and Richard Cornes. Independence of allocative efficiency from distribution in the theory of public goods. Econometrica, 51(6):1753-1765, November 1983.

[2] Theodore Bergstrom. The Value of Life and Safety, chapter When is a Man's Life worth more than his human capital?, pages 3-26. North Holland, Amsterdam, 1982.

[3] Theodore Bergstrom. Love and spaghetti, the opportunity cost of virtue. Journal of Economic Perspectives, 3(2):165-173, Spring 1989.

[4] Theodore Bergstrom. Systems of benevolent utility functions. Journal of Public Economic Theory, 1(2):71-100, 1999.

[5] J. M. Bowker and John R. Stoll. Use of dichotomous nonmarket methods to value the whooping crane resource. American Journal of Agricultural Economics, 70(2):372-381, 1988.

[6] Richard T. Carson. Contingent valuation: A user's guide. Technical report, Dept of Economics, University of California San Diego, December 1999.

[7] John Chipman and James Moore. The new welfare economics 1939-1974. International Economic Review, 19(3):547-584, October 1978.

[8] John Chipman. The New Palgrave A Dictionary of Economics, chapter Compensation Principle, pages 524-531. Macmillan Press, London, 1987.

[9] Don Coursey. The revealed demand for a public good: evidence from threatened and endangered species. New York University Environmental Law Journal, VI(2):411-450, 1997. 
[10] Mark Dickie and Shelby Gerking. Valuing children's health: parental perspectives. Technical report, University of Central Florida, Dept of Economics, UCF, Orlando Fl 32826, 2003.

[11] Mark Dickie and Victoria Ulery. Parental altruism and the value of avoiding acute illness: Are kids worth more than parents. Technical report, University of Central Florida, Dept of Economics, UCF, Orlando Fl 32826, 2002 .

[12] W. Michael Hanemann. Valuing the environment through contingent valuation. Journal of Economic Perspectives, 8(4):19-43, Fall 1994.

[13] John R. Hicks. The foundations of welfare economics. Economic Journal, 49(196), 1939.

[14] Per-Olov Johansson. Altruism and the value of statistical life: empirical implications. Journal of Health Economics, 13(1):111-118, March 1994.

[15] Michael Jones-Lee, M Hamerton, and P.R. Philips. The value of safety: Results of a national survey. Economic Journal, 95(377):49-72, March 1985 .

[16] Michael Jones-Lee. Altruism and the value of other people's safety. Journal of Risk and Uncertainty, 4:213-219, 1991.

[17] Michael Jones-Lee. Paternalistic altruism and the value of statistical life. Economic Journal, 102(410):80-90, January 1992.

[18] Nicholas Kaldor. Welfare propositions of economics and interpersonal comparisons of utility. Economic Journal, 49(195):549-552, September 1939.

[19] John Loomis and Douglas White. Economic benefits of rare and endangered species: summary and meta-analysis. Ecological Economics, 18:197-206, 1996.

[20] Paul Milgrom. Is sympathy an economic value? philosophy, economics, and the contingent valuation method. In J. A. Hausman, editor, Contingent valuation a critical assessment, pages 417-442. North-Holland, Amsterdam, 1993.

[21] Paul Samuelson. Evaluation of real national income. Oxford Economic Papers, 2(1):1-29, January 1950.

[22] Paul Samuelson. The pure theory of public expenditures. Review of Economics and Statistics, 36(4):387-389, 1954. 
[23] Thomas Stevens, Jaime Echeverria, Ronald Glass, Tim Hager, and Thomas More. Measuring the existence value of wildlife: what do cvm estimates really show? Land Economics, 67(4):390-400, November 1991.

[24] Thomas Stevens, Thomas More, and Ronald Glass. Interpretation and temporal stability of cv bids for wildlife existence: a panel study. Land Economics, 70(3):355-363, August 1994.

[25] W. Kip Viscusi and Joseph E. Aldy. The value of a statistical life: A critical review of market estimates throughout the world. Technical Report 9487, National Bureau of Economic Research, 1050 Massachusetts Avenue, Cambridge, MA, February 2003.

[26] W. Kip Viscusi, Wesley A. Magat, and Anne Forrest. Altruistic and private valuations of risk reduction. Journal of Policy Analysis and Management, 7(2):227-245, 1988. 